\title{
Hybrid surgery with PEEK rods for lumbar degenerative diseases: a 2-year follow-up study
}

\author{
Yao Zhao ${ }^{\dagger}$, Beiyu Xu ${ }^{\dagger}$, Longtao Qi, Chunde Li*, Lei Yue, Zhengrong Yu, Shijun Wang and Haolin Sun
}

\begin{abstract}
Background: Finite element analyses and biomechanical tests have shown that PEEK rods promote fusion and prevent adjacent segment degeneration. The purpose of this study was to evaluate the effects and complications of hybrid surgery with PEEK rods in lumbar degenerative diseases.

Methods: From January 2015-December 2017, 28 patients who underwent lumbar posterior hybrid surgery with PEEK rods were included in the study. The patients were diagnosed with lumbar disc herniation, lumbar spinal stenosis, or degenerative grade I spondylolisthesis. Before the operation and at the last follow-up, the patients completed lumbar anteroposterior and lateral X-ray, dynamic X-ray, MRI examinations. In addition, at the last follow-up the patients also completed lumbar CT examinations. The radiographic parameters, clinical visual analog scale (VAS) score and Oswestry disability index (ODI) score were compared.

Results: The average age of the patients was $44.8 \pm 12.6$ years, and the average follow-up duration was $26.4 \pm 3.6$ months. The VAS score improved from $6.3 \pm 1.6$ to $1.0 \pm 0.9$, and the ODI score decreased from $38.4 \pm 10.8$ to $6.8 \pm$ 4.6. The fusion rate of the fused segment was $100 \%$. There were no significant changes in the modified Pfirrmann classifications or disc height index for the nonfused segments and the upper adjacent segments from pre- to postoperatively. No cases of screw loosening, broken screws, broken rods or other mechanical complications were found.
\end{abstract}

Conclusion: Hybrid surgery with PEEK rods for lumbar degenerative diseases can yield good clinical results and effectively reduce the incidence of complications such as adjacent segment diseases.

Keywords: Lumbar degenerative diseases, PEEK rods, Hybrid surgery, Adjacent segment diseases

\section{Background}

Lumbar decompression with fusion surgery is currently a common treatment for lumbar degenerative diseases. Titanium rods are widely used and can yield sufficient stability and a high fusion rate. However, due to the large elastic modulus of titanium rods, shortcomings, such as stress shielding in the intervertebral bone graft area and increased stress on adjacent segmental discs and facet joints, can occur, thereby increasing the risk of adjacent

*Correspondence: lichunde@vip.sina.com

†Yao Zhao and Beiyu Xu are co-first authors.

Department of Orthopaedics, Peking University First Hospital, Xicheng

District, Beijing 100034, China segment disease (ASD). The annual incidence rate of ASD has been reported to be 2-3\% [1]. A 10-year followup study of patients with single-segment lumbar fusion by titanium rods showed that the incidence of radiological ASD was $75 \%$, the incidence of symptomatic ASD was $31 \%$, and the rate of revision surgery due to ASD was $15 \%$, where $77 \%$ of revisions were due to cranial degeneration [2]. ASD can cause back pain, radiating pain and numbness in the lower limbs, restrict the patient's ability to perform activities and reduce their quality of life.

With the development of suitable biomechanical materials, elastic fixation and semirigid fixation have emerged. Elastic fixation, such as the Dynesys system, retains the mobility of the corresponding segment but increases the original author(s) and the source, provide a link to the Creative Commons licence, and indicate if changes were made. The images or other third party material in this article are included in the article's Creative Commons licence, unless indicated otherwise in a credit line to the material. If material is not included in the article's Creative Commons licence and your intended use is not permitted by statutory regulation or exceeds the permitted use, you will need to obtain permission directly from the copyright holder. To view a copy of this licence, visit http://creativecommons.org/licenses/by/4.0/. The Creative Commons Public Domain Dedication waiver (http://creativecommons.org/publicdomain/zero/1.0/) applies to the data made available in this article, unless otherwise stated in a credit line to the data. 
stress at the screw-bone interface, which increases the risk of screw loosening. Payer et al. [3] used the Dynesys system to treat patients with single-segment degenerative spondylolisthesis and spinal stenosis, and the results showed that it could not effectively prevent the occurrence of ASD. A 5-year follow-up study showed that the incidence of screw loosening was as high as $20 \%$ [4].

Semirigid fixation, with systems such as the polyetheretherketone (PEEK) rod system, has been used in lumbar spine surgery since 2007 [5]. The PEEK material has good levels of biocompatibility, nontoxicity, and corrosion resistance. Its elastic modulus is approximately $3.2 \mathrm{GPa}$, which is between those of cancellous bone and cortical bone and is significantly lower than the that of titanium rods, which is $114 \mathrm{GPa}$ [6]. Compared with titanium rods, PEEK rods increase the load on the anterior column, allow the fixed segment to move slightly, reduce the stress shielding effect, and reduce the stress on the interface between the bone and screw [7-9]. In addition, PEEK rods are transparent on X-ray fluoroscopy; therefore, the range of artifacts is small during CT and MRI examinations.

Previous clinical studies have shown that PEEK rods can achieve satisfactory results in lumbar short-segment fusion and are not inferior to the current "gold standard" titanium rods [10]. ASD is a common complication of lumbar fusion surgery. The risk factors include an age over 60 years, obesity, preoperative disc and facet joint degeneration, long-segment fusion, and insufficient lumbar lordosis (LL) recovery [11]. In some special cases, such as in patients with significant degeneration of adjacent segments, PEEK rods are more advantageous in theory. Topping-off surgery refers to the use of a stabilizing device above the lumbar fusion segment, which also has a potential preventive effect on proximal ASD [12]. At present, the clinical research on PEEK rods is relatively scarce. This study aimed to determine the clinical efficacy of topping-off hybrid surgery with PEEK rods in treating lumbar degenerative diseases and its impact on ASD.

\section{Methods}

Patients who underwent two-segment hybrid surgery with PEEK rods in our hospital due to lumbar disc herniation between January 2015 and December 2017 were recruited. The research was approved by the Ethics Committee of Peking University First Hospital (No. 2015 [953]). Before surgery, the patients completed lumbar X-ray, dynamic X-ray and MRI examinations. The affected segments (fusion segment) were located at L5/ S1 or L4/5 and were treated with decompression and intervertebral fusion. Indications for fusion included: (1) huge disc herniation with prolapse of the annulus fibrosus and cartilage endplate, and serious destruction of intervertebral disc structure; (2) dynamic radiograph showed lumbar instability (slippage $\geqq 3 \mathrm{~mm}$ ); (3) the decompression range exceeded $1 / 3$ of the facet joint, or it affected the stability of the lumbar spine; (4) extreme lateral intervertebral disc herniation requiring resection of facet joint. There was significant degeneration in the upper adjacent segments (nonfusion segment), according to findings such as a low signal intensity of the disc on T2 phase images, a high-intensity zone (HIZ) behind the disc, a reduced intervertebral height, lumbar disc herniation without nerve compression, combined with grade 1 stenosis [13] or degenerative spondylolisthesis (Meyerding I), and the segments were fixed without fusion. The exclusion criteria included lumbar spondylolysis, lumbar tumors, spinal deformities, a history of lumbar surgery, and related conditions. At the 2-year follow-up, lumbar X-ray, dynamic X-ray, CT and MRI scans were performed. The VAS scores and ODI scores were recorded pre- and postoperatively.

The radiological parameters included the preoperative and postoperative values of $\mathrm{LL}$, pelvic incidence (PI), fixed-segment lordosis and range of motion (ROM), nonfusion segment and upper adjacent segment lordosis, disc height index (DHI) (Fig. 1), and modified Pfirrmann classification [14] of the discs.

SPSS version 22.0 (IBM, Armonk, NY, USA) was used for statistical analysis, and the average and standard deviation of each parameter were calculated. The preoperative and postoperative modified Pfirrmann classification were determined using Wilcoxon signed ranks test, and the other parameters were determined using paired-sample $t$ tests, and $p$ values $<0.05$ were considered to indicate significant differences.

\section{Results}

There were 39 patients who underwent hybrid surgery, 28 of whom completed the 2-year follow-up and were included in this study. The general information of the patients is shown in Table 1 . One patient had cerebrospinal fluid leakage due to the adhesion of the intervertebral disc and dural sac during the operation, which was repaired by sutures. Fat liquefaction occurred in 1 patient, and delayed healing occurred in 1 patient due to a superficial wound infection. At the two-year follow-up, the fusion rate was $100 \%$, as evidenced by CT. There were no mechanical complications, such as screw loosening or screw and rod breakage, and no patients required revision surgery due to complications.

The VAS score improved from $6.3 \pm 1.6$ to $1.0 \pm 0.9$ $(p<0.05)$, and the ODI score decreased from $38.4 \pm 10.8$ to $6.8 \pm 4.6(p<0.05)$. The magnitudes of improvement in pain and function were significant. 


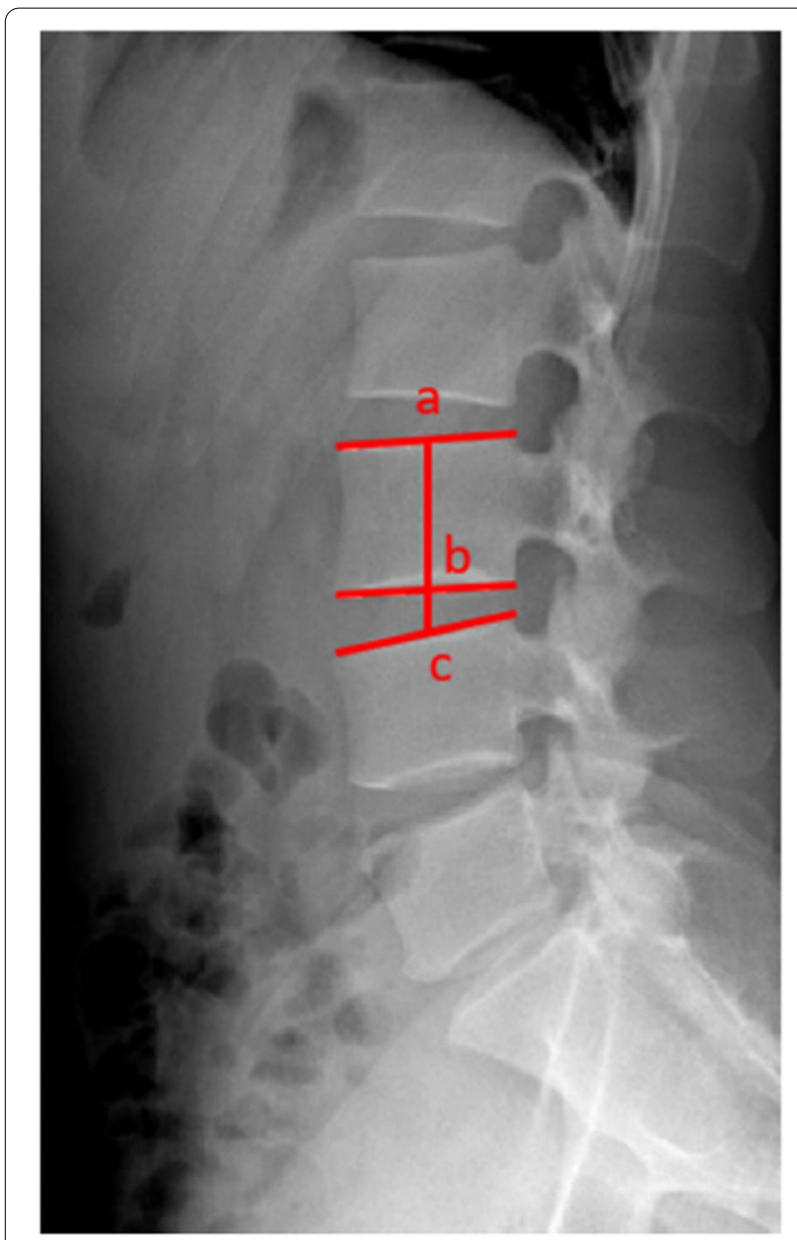

Fig. 1 Schematic diagram of the disc height index (DHI). The midpoints of the upper and lower endplates of the upper vertebral body are marked as a and $b$, respectively, and the midpoint of the upper endplate of the lower vertebral body is marked as c, DHI=bc/ $a b$

Table 1 General information of the patients

\begin{tabular}{ll}
\hline Age (years) & $44.8 \pm 12.6(28-71)$ \\
Sex (male/female) & $18 / 10$ \\
BMI (kg/m²) & $25.5 \pm 3.5(20.2-34.3)$ \\
Follow-up duration (months) & $26.4 \pm 3.6(21-36)$ \\
Surgical segments (L3-5/L4-S1) & $9 / 19$ \\
Operation time (minute) & $155.4 \pm 23.0(110-210)$ \\
Intraoperative bleeding (ml) & $162.5 \pm 64.7(50-300)$ \\
\hline
\end{tabular}

The comparison of radiological parameters from preto postoperatively is shown in Table 2 . There were no significant changes in the modified Pfirrmann classifications or DHI of the intervertebral disc at the nonfusion segment and its adjacent segment from preoperatively to the two-year follow-up. The lordosis of the nonfusion segment decreased from an average of $10.5^{\circ}$ to $8.3^{\circ}$, and the lordosis of the upper adjacent segment increased from an average of $9.3^{\circ}$ to $10.7^{\circ}$. The changes were significant. The fixed-segment ROM significantly decreased from an average of $10.0^{\circ}$ to $2.6^{\circ}$. There were no significant changes in fixed-segment lordosis, LL or PI from before to after the operation. The typical case is shown in Figs. 2 and 3.

Pearson correlation analysis showed that there was a significant positive correlation between postoperative fixed-segment lordosis and preoperative fixed-segment lordosis and LL $(p<0.05)$, with $r=0.695$ and 0.558 , respectively. There were no significant correlations between fixed-segment mobility and other factors.

\section{Discussion}

Lumbar degenerative disease begins with degeneration of a lumbar intervertebral disc, most commonly at the L4/5 and L5/S1 segments. In clinical practice, multiple disc degeneration is often seen. Due to a decrease in water content and the elasticity of the disc, the stress on the facet joint becomes abnormal, and the stability of the lumbar spine decreases. It is still controversial whether to perform fusion surgery for lumbar degenerative spondylolisthesis. Recently, the NORDSTEN-DS trial showed that decompression alone was noninferior to decompression with instrumented fusion over a period of 2 years. Reoperation occurred somewhat more often in the decompression-alone group than in the fusion group [15]. However, the American SLIP trial showed significantly better results for fusion. The patients in this study had huge disc herniation and lumbar instability at affected segment, we preferred fusion surgery [16]. Titanium rods are the most widely used rods for fusion. However, long-term follow-up results have shown that the risk of adjacent segment degeneration is as high as $75 \%$ [2]. The patients had multisegment degeneration, and the average body mass index (BMI) was $25.5 \mathrm{~kg} / \mathrm{m}^{2}$. Because obesity is also a risk factor for ASD [11], for these patients, we tended to choose hybrid surgery with PEEK rods to reduce the risk of ASD. Since 18 patients in this study underwent L4-S1 fixation and ASD mostly occurred in the upper adjacent segment [2], this article mainly evaluated cases in the upper adjacent segment.

The modified Pfirrmann classification of the nonfusion segment was 5.0 preoperatively and 4.9 at the 2-year follow-up, and the DHI was 0.34 preoperatively and 0.33 at the 2-year follow-up, showing these parameters hardly changed. Mesbah et al. [17] simulated L4/5 fusion with titanium rods and L3-5 hybridization with PEEK rods with finite element analysis, and the results showed that PEEK rods can significantly reduce the pressure of the L3/4 disc during flexion, extension, and lateral flexion. 
Table 2 Comparison of radiological parameters from pre- to postoperatively

\begin{tabular}{|c|c|c|c|}
\hline Radiological parameters & Preoperation & 2-year follow-up & $P$ value \\
\hline Modified Pfirrmann classification of nonfusion segment & $5.0 \pm 1.0$ & $4.9 \pm 1.1$ & 0.102 \\
\hline DHI of nonfusion segment & $0.34 \pm 0.07$ & $0.33 \pm 0.05$ & 0.233 \\
\hline Lordosis of nonfusion segment $\left(^{\circ}\right)$ & $10.5 \pm 4.3$ & $8.3 \pm 3.0$ & 0.005 \\
\hline Modified Pfirrmann classification of upper adjacent segment & $3.3 \pm 1.2$ & $3.4 \pm 1.2$ & 0.655 \\
\hline DHI of upper adjacent segment & $0.34 \pm 0.04$ & $0.33 \pm 0.04$ & 0.450 \\
\hline Lordosis of upper adjacent segment $\left(^{\circ}\right)$ & $9.3 \pm 3.6$ & $10.7 \pm 3.7$ & 0.010 \\
\hline Lordosis of fixed-segment $\left(^{\circ}\right)$ & $27.5 \pm 9.3$ & $26.8 \pm 6.4$ & 0.612 \\
\hline Lordosis of fixed-segment at flexion position $\left(^{\circ}\right)$ & $21.2 \pm 9.2$ & $25.3 \pm 6.9$ & 0.004 \\
\hline Lordosis of fixed-segment at extension position $\left(^{\circ}\right)$ & $31.2 \pm 9.4$ & $27.8 \pm 7.0$ & 0.015 \\
\hline ROM of fixed-segment $\left(^{\circ}\right)$ & $10.0 \pm 3.9$ & $2.6 \pm 1.2$ & 0.000 \\
\hline $\mathrm{LL}\left({ }^{\circ}\right)$ & $43.0 \pm 14.6$ & $44.4 \pm 11.0$ & 0.411 \\
\hline $\mathrm{PI}\left({ }^{\circ}\right)$ & $45.1 \pm 9.2$ & $45.8 \pm 8.8$ & 0.225 \\
\hline
\end{tabular}

The titanium rods increased the stress on the L3/4 facet joints by $152 \%$, while the PEEK rods reduced the stress on the L3/4 facet joints by $25 \%$. Because the PEEK rods provided support to the nonfusion segment, they reduced the stress on the disc and the facet joint, so these rods might protect the degenerated segment.

Preoperatively, the modified Pfirrmann classification of the upper adjacent segment was 3.3, and the DHI was 0.34. At the 2-year follow-up, the modified Pfirrmann classification was 3.4, and the DHI was 0.33, showing these parameters hardly changed. Obvious adjacent segment degeneration was not seen. Hsieh et al. [18] established a finite element model of L4/5 fusion with connecting rods of different materials. The results showed that compared with titanium rods, PEEK rods could reduce the stress on the facet joints and disc of the upper adjacent segment and increase the stress on the intervertebral cage and bone graft. De Lure et al. [19] reviewed the data of 30 patients who underwent fusion surgery with PEEK rods, and ASD was not found at the follow-up performed at an average of 18 months postoperatively. In this study, hybrid surgery was performed to form a buffer between the fixed vertebrae and the normal vertebrae and reduce the stress. We believe that it had a helped prevent ASD, and the short-term follow-up results were good.

The biomechanical tests showed that titanium rods and PEEK rods can provide similar levels of stability. Although both types of rods can significantly reduce the mobility of the fixed segment ( $>70 \%$ ), PEEK rods can provide greater all-directional mobility than can titanium rods [20-22]. The finite element analysis showed that compared with titanium rods, PEEK rods can increase the range of flexion and extension, lateral flexion and axial rotation by 1.8-2.1, 7-7.2 and 3.7-3.8 times, respectively [23, 24]. Biswas et al. [24] performed finite element analysis and reported that the mobility of the fixed segment of PEEK rods was $4.2^{\circ}-6.2^{\circ}$ in flexion and $4.2^{\circ}-1.1^{\circ}$ in extension. Huang et al. [25] used the nonfusion technique with PEEK rods to treat lumbar degenerative diseases. There were no significant changes in the height of the disc at the treated segment during the 2 -year follow-up period, and the ROM was $1.8^{\circ}$. In this study, the motion of the fixed segment was $2.6^{\circ}$, which confirmed that PEEK rods do allow the fixed segment to move slightly, consistent with the results of finite element analysis.

The restoration of a normal LL curve is very important. Ideally, $\mathrm{LL}=\mathrm{PI} \pm 9^{\circ}$ [26]. In this study, the postoperative LL was $44.4^{\circ}$, which was similar to the postoperative PI value of $45.8^{\circ}$, and the difference was not significant. The lordosis of the fixed segment was $26.8^{\circ}$, which was not significantly different from the preoperative lordosis, but the postoperative lordosis of the nonfused segment was $8.3^{\circ}$, which was $2.2^{\circ}$ less than that before the operation, and the difference was significant. Because PEEK rods cannot be bent during the operation, it suggested that PEEK rods are still slightly insufficient in restoring lordosis. The postoperative lordosis of the upper adjacent segment was $10.7^{\circ}$, which was increased by $1.4^{\circ}$ to retain the LL. Ogrenci et al. [27] reported the mid-term follow-up results of 172 patients treated with PEEK rods. The average LL was $42.5^{\circ}$ preoperatively and $44.0^{\circ}$ postoperatively. The authors also believed that PEEK rods are less effective in restoring LL and reconstructing sagittal balance. Therefore, for patients with high PI $\left(>55^{\circ}\right)$, PEEK rods might have adverse effects on sagittal balance. In the future, PEEK rods should be designed with different radians according to the PI value of the patients to solve this problem. 

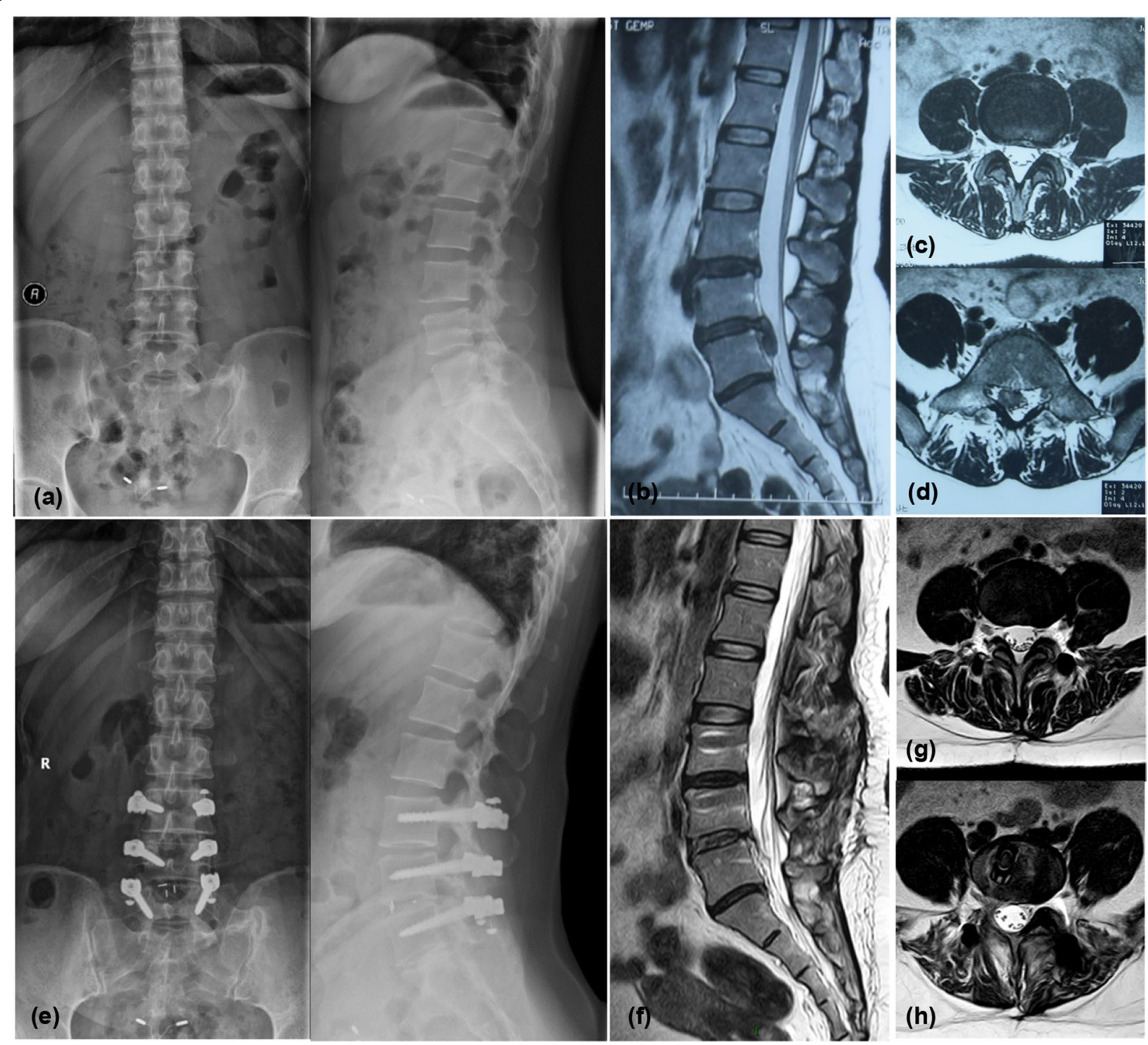

Fig. 2 Typical case. The patient was a 40-year-old woman who was diagnosed with lumbar disc herniation (L4/5), cauda equina syndrome, and $\mathrm{L} 3 / 4$ disc degeneration and underwent L3-5 hybrid surgery with PEEK rods. a shows the lumbar X-ray before the operation. $\mathbf{b}$ shows the sagittal-plane MRI image of the lumbar region before the operation.c, $\mathbf{d}$ show the MRI images of the $L 3 / 4$ and $L 4 / 5$ sections of the lumbar region before the operation, respectively. e shows the lumbar X-ray at the 2-year follow-up. $\mathbf{f}$ shows the sagittal MRI image of the lumbar region at the 2-year follow-up. $\mathbf{g}, \mathbf{h}$ show the MRI images of the $L 3 / 4$ and $L 4 / 5$ sections of the lumbar region at the 2-year follow-up, respectively. L3-5 were fixed segments, L3/4 was nonfused segments, the modified Pfirrmann classification of L3/4 was 6 both pre- and postoperatively, and the DHI was 0.28 preoperatively and 0.26 postoperatively. The modified Pfirrmann classification of the upper adjacent segment L2/3 was 2 both pre- and postoperatively, and the $\mathrm{DHI}$ was 0.33 preoperatively and 0.35 postoperatively. No significant degeneration was seen

Under normal physiological conditions, the lumbar disc bore approximately $80 \%$ of the stress, and the posterior facet bore $20 \%$ of the stress [28]. When the PEEK rods were used, the pressure on the front column was $59 \%$, which was higher than that when the titanium rods were used, which was $55 \%$ [29]. Increasing the load on the anterior column can reduce the stress shielding effect and promote bone graft fusion. In this study, the fusion rate of the fused segment was $100 \%$, which is consistent with the findings of Qi et al [30].

No mechanical complications, such as screw loosening or screw and rod breakage, were found in this study. Meta-analysis showed that the fusion rate of PEEK rods was as high as $95.6 \%$, and the incidence rates of screw breakage and screw loosening were 2.6 and $2.0 \%$, respectively [10]. Huang et al. [25] found that in 31 patients, 

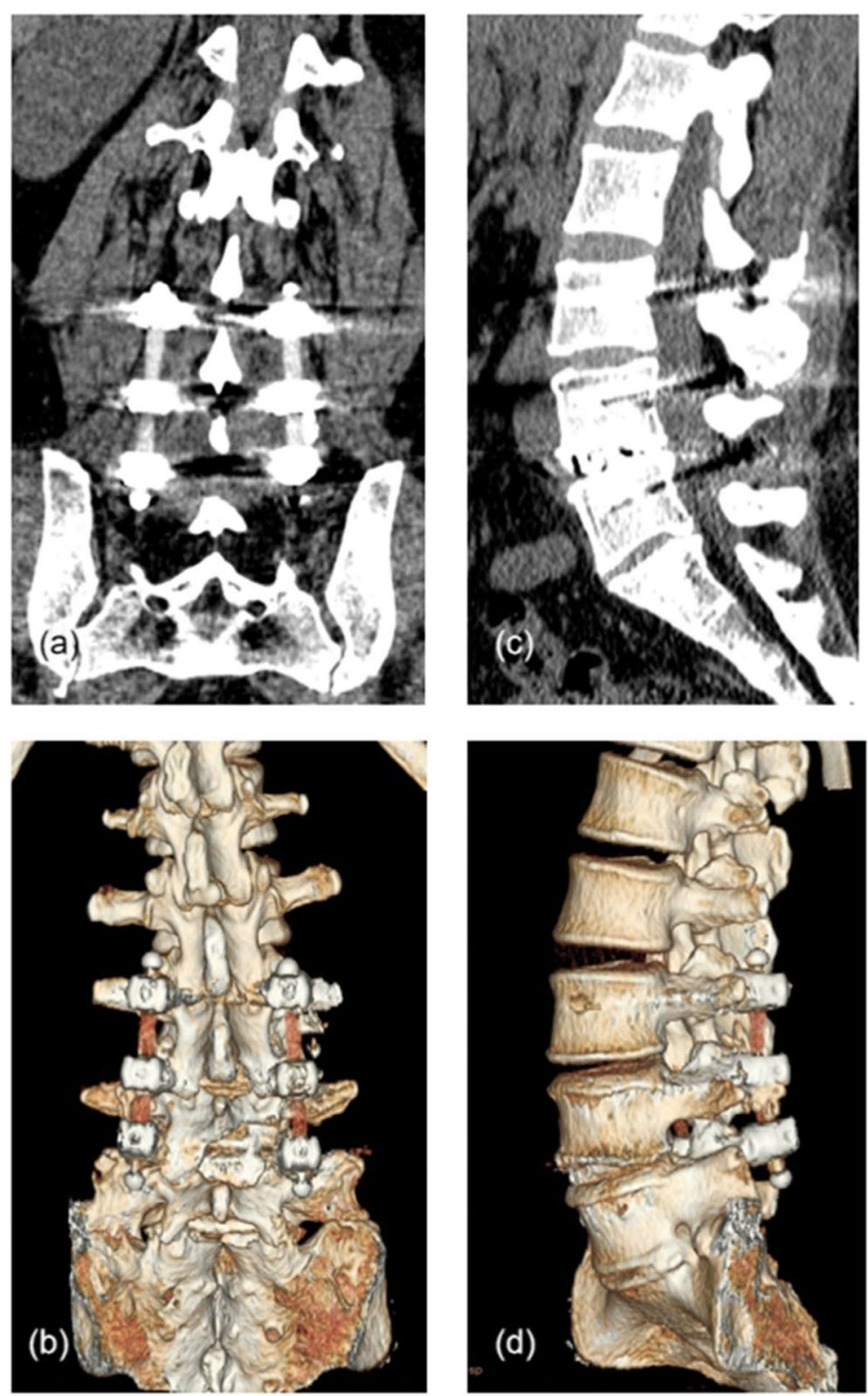

Fig. 3 Typical case. a, b Coronal lumbar CT scan and 3D reconstruction taken at the 2-year follow-up, showing the contours of the bilateral PEEK rods. c, d Sagittal plane image and 3D reconstruction showing intervertebral fusion was achieved at the $L 4 / 5$ segment

only one patient had a halo zone around the screw on radiography, and the patient did not have clinical symptoms. Lure et al. [19] reported that 1 of 30 patients underwent revision surgery due to screw loosening. In this case, the patient had a flat back deformity, and the fixation length was 4 segments. Ormond et al. [31] reported that the fusion rate of PEEK rods in the treatment of lumbar degenerative diseases was $89.3 \%$, and the revision rate was $19.1 \%$, where $62.5 \%$ of the revisions were due to ASD. A possible explanation for this finding is that there were many smokers among the enrolled patients, and the article did not report whether there was degeneration in the adjacent segments before surgery. Krieg et al. [32] reported 322 patients with an average age of 69.1 years who received PEEK rods during topping-off hybrid surgery. Among these patients, 18\% developed ASD, and the average time of appearance was 26.5 months after surgery. A total of $21.1 \%$ of patients had a halo zone around the screws, and $16.4 \%$ of patients required revision surgery. These findings were quite different from 
ours. The possible reasons are as follows: the average age of the patients in this study was 44.8 years old, and the incidence of ASD is higher in patients over 50 years old [33]. Because the patients were relatively young, the bone condition was better, and the intervertebral fusion rate reached $100 \%$, reducing the risk of screw loosening. In addition, the average number of fixed segments was 3.2in the study by Krieg et al. [19] and 2 in our study. Long segment fixation might also affect ASD [11].

PEEK rods have some elasticity, so the risk of rod breakage was low. Cases of rod breakage have rarely been reported in the literature. Kurtz et al. [34] reported 12 cases of revision surgery, and PEEK rods were retrieved, but none of them were broken. In a mid-term followup study reported by Ogrenci et al. [27], rod breakage occurred in 1 of 172 patients. Although PEEK rods are invisible on X-ray images, the contours of the rods are visible on $\mathrm{CT}$ images. No cases of broken rods were found in our study.

The VAS score and ODI score significantly improved, which is consistent with the results of previous studies $[19,25,27]$. Sarbello et al. [35] considered that the radiolucency of the PEEK rods might affect the perceptions of the patients. The patients who received PEEK rods tended to have better outcomes. Meta-analysis showed that the postoperative improvement rate of clinical function was $67.4 \%$, which was similar to that associated with titanium rods [10].

This study has the following shortcomings. First, it was a retrospective study and lacked a randomized control group. Second, the sample size was small, and there might be selection bias. In addition, the follow-up period was short. At present, the number of clinical trials on hybrid surgery with PEEK rods is very small, and there is a lack of long-term follow-up results. Additional research is still needed to confirm the clinical efficacy of hybrid surgery with PEEK rods.

\section{Conclusion}

In patients with the appropriate indications, hybrid surgery with PEEK rods could be performed to treat twosegment lumbar degenerative diseases. Compared with titanium rods, PEEK rods can theoretically increase the load on the anterior column of the vertebral body to promote intervertebral fusion and simultaneously reduce the pressure on the discs and articular processes of the upper adjacent segments to reduce the risk of ASD. In this study, there were no cases of ASD, screw loosening, breakage or other mechanical complications at the 2-year follow-up. The clinical symptoms improved satisfactorily. Additional long-term and large-scale clinical studies are needed to confirm the clinical efficacy of PEEK rod hybrid surgery.

\section{Abbreviations}

PEEK: Polyetheretherketone; MRI: Magnetic Resonance Imaging; CT: Computed Tomography; VAS: Visual Analog Scale; ODI: Oswestry Disability Index; ASD: Adjacent Segment Disease; LL: Lumbar Lordosis; PI: Pelvic Incidence; ROM: Range of Motion; DHI: Disc Height Index; NORDSTEN-DS trial: The Norwegian Degenerative Spondylolisthesis and Spinal Stenosis; SLIP Trial: Spinal Laminectomy versus Instrumented Pedicle Screw Trial.

\section{Supplementary Information}

The online version contains supplementary material available at https://doi. org/10.1186/s12891-021-04895-1.

\section{Additional file 1.}

\section{Acknowledgements}

Not applicable.

\section{Authors' contributions}

$Y Z$ and $B Y X$ contributed equally to this work. $Y Z$ and BYX wrote the main manuscript text. YZ, BYX, and LTQ collected the data. CDL designed the study and revised the manuscript. LTQ and YL analyzed the data. ZRY, SJW, and HLS edited the manuscript. All authors read and approved the final manuscript.

Funding

No funding.

Availability of data and materials

The datasets analyzed during the current study are available from the corresponding author on reasonable request.

\section{Declarations}

Ethics approval and consent to participate

This retrospective research was approved by the Ethics Committee of Peking University First Hospital (No. 2015 [953]). Written informed consent was obtained from all participants. All methods were carried out in accordance with relevant guidelines and regulations.

\section{Consent for publication}

Not applicable.

\section{Competing interests}

No conflict of interest.

Received: 1 April 2021 Accepted: 18 November 2021

Published online: 03 January 2022

\section{References}

1. Radcliff KE, Kepler CK, Jakoi A, et al. Adjacent segment disease in the lumbar spine following different treatment interventions. Spine J. 2013;13(10):1339-49.

2. Okuda S, Nagamoto Y, Matsumoto T, et al. Adjacent segment disease after single segment posterior lumbar Interbody fusion for degenerative Spondylolisthesis: minimum 10 years follow-up. Spine (Phila Pa 1976). 2018;43(23):E1384-8.

3. Payer M, Smoll NR, Oezkan N, et al. Dynamic transpedicular stabilisation and decompression in single-level degenerative anterolisthesis and stenosis. Acta Neurochir. 2014;156(2):221-7.

4. Sapkas G, Mavrogenis AF, Starantzis KA, et al. Outcome of a dynamic neutralization system for the spine. Orthopedics. 2012;35(10):e1497-502.

5. Highsmith JM, Tumialán LM, Rodts GE Jr. Flexible rods and the case for dynamic stabilization. Neurosurg Focus. 2007;22(1):E11. 
6. Ahn YH, Chen WM, Lee KY, et al. Comparison of the load-sharing characteristics between pedicle-based dynamic and rigid rod devices. Biomed Mater. 2008;3(4):044101.

7. Jahng TA, Kim YE, Moon KY. Comparison of the biomechanical effect of pedicle-based dynamic stabilization: a study using finite element analysis. Spine J. 2013;13(1):85-94.

8. Turner JL, Paller DJ, Murrell CB, et al. The mechanical effect of commercially pure titanium and Polyetheretherketone rods on spinal implants at the operative and adjacent levels. Spine (Phila Pa 1976). 2010;35(21):E1076-82.

9. Chou WK, Chien A, Wang JL, et al. Biomechanical analysis between PEEK and titanium screw-rods spinal construct subjected to fatigue loading. J Spinal Disord Tech. 2015;28(3):E121-5.

10. Selim A, Mercer S, Tang F, et al. Polyetheretherketone (PEEK) rods for lumbar fusion: a systematic review and Meta-analysis. Int J Spine Surg. 2018;12(2):190-200.

11. Chen BL, Wei FX, Ueyama K, et al. Adjacent segment degeneration after single-segment PLIF: the risk factor for degeneration and its impact on clinical outcomes. Eur Spine J. 2011;20(11):1946-50.

12. Chou PH, Lin HH, An HS, et al. Could the topping-off technique be the preventive strategy against adjacent segment disease after pedicle screw-based fusion in lumbar degenerative diseases? A systematic review. Biomed Res Int. 2017;2017:4385620.

13. Lee GY, Lee JW, Choi HS, et al. A new grading system of lumbar central canal stenosis on MRI: an easy and reliable method. Skelet Radiol. 2011;40(8):1033-9.

14. Griffith JF, Wang YX, Antonio GE, et al. Modified Pfirrmann grading system for lumbar intervertebral disc degeneration. Spine. 2007;32(24):E708-12.

15. Bydon M, Alvi MA, Goyal A, et al. Degenerative lumbar Spondylolisthesis: definition, natural history, conservative management, and surgical treatment. Neurosurg Clin N Am. 2019;30(3):299-304.

16. Ghogawala Z, Dziura J, Butler WE, et al. Laminectomy plus fusion versus laminectomy alone for lumbar Spondylolisthesis. N Engl J Med. 2016;374(15):1424-34

17. Mesbah M, Abdelwahed B. Biomechanical investigation of the effect of pedicle-based hybrid stabilization constructs: a finite element study. Proc Inst Mech Eng H. 2020;234(9):931-41.

18. Hsieh YY, Tsuang FY, Kuo YJ, et al. Biomechanical analysis of single-level interbody fusion with different internal fixation rod materials: a finite element analysis. BMC Musculoskelet Disord. 2020;21(1):100

19. De lure F, Bosco G, Cappuccio M, et al. Posterior lumbar fusion by peek rods in degenerative spine: preliminary report on 30 cases. Eur Spine J. 2012;21(Suppl 1):S50-4

20. Abode-lyamah K, Kim SB, Grosland N, et al. Spinal motion and intradiscal pressure measurements before and after lumbar spine instrumentation with titanium or PEEK rods. J Clin Neurosci. 2014;21(4):651-5.

21. Zhou R, Huang Z, Liu X, et al. Kinematics and load-sharing of an anterior thoracolumbar spinal reconstruction construct with PEEK rods: An in vitro biomechanical study. Clin Biomech (Bristol, Avon). 2016;40:1-7.

22. Yeager MS, Cook DJ, Cheng BC, et al. In vitro comparison of Dynesys, PEEK, and titanium constructs in the lumbar spine. Adv Orthop. 2015;2015:895931.

23. Biswas JK, Roy S, Rana M, et al. A comparison of rigid, semi-rigid and flexible spinal stabilization devices: a finite element study. Proc Inst Mech Eng H. 2019;233(12):1292-8.

24. Biswas JK, Rana M, Majumder S, et al. Effect of two-level pedicle-screw fixation with different rod materials on lumbar spine: a finite element study. J Orthop Sci. 2018;23(2):258-65.

25. Huang W, Chang Z, Song R, et al. Non-fusion procedure using PEEK rod systems for lumbar degenerative diseases: clinical experience with a 2-year follow-up. BMC Musculoskelet Disord. 2016;1(17):53.

26. Schwab F, Ungar B, Blondel B, et al. Scoliosis Research Society-Schwab adult spinal deformity classification: a validation study. Spine (Phila Pa 1976). 2012;37(12):1077-82.

27. Ogrenci A, Koban O, Yaman O, et al. Polyetheretherketone rods in lumbar spine degenerative disease: mid-term results in a patient series involving radiological and clinical assessment. Turk Neurosurg. 2019;29(3):392-9.

28. Sengupta DK. Dynamic stabilization devices in the treatment of low back pain. Orthop Clin North Am. 2004;35(1):43-56.
29. Sengupta DK, Bucklen B, McAfee PC, et al. The comprehensive biomechanics and load-sharing of Semirigid PEEK and Semirigid posterior dynamic stabilization systems. Adv Orthop. 2013;2013:745610.

30. Qi L, Li M, Zhang S, et al. Comparative effectiveness of PEEK rods versus titanium alloy rods in lumbar fusion: a preliminary report. Acta Neurochir. 2013;155(7):1187-93.

31. Ormond DR, Albert L Jr, Das K, et al. Polyetheretherketone (PEEK) rods in lumbar spine degenerative disease: a case series. Clin Spine Surg. 2016:29(7):E371-5.

32. Krieg SM, Balser N, Pape $H$, et al. Topping-off technique for stabilization of lumbar degenerative instabilities in 322 patients. J Neurosurg Spine. 2019;15:1-7.

33. Cheh $\mathrm{G}$, Bridwell KH, Lenke LG, et al. Adjacent segment disease following lumbar/thoracolumbar fusion with pedicle screw instrumentation: a minimum 5-year follow-up. Spine (Phila Pa 1976). 2007;32(20):2253-7.

34. Kurtz SM, Lanman TH, Higgs $G$, et al. Retrieval analysis of PEEK rods for posterior fusion and motion preservation. Eur Spine J. 2013;22(12):2752-9.

35. Sarbello JF, Lipman AJ, Hong J, et al. Patient perception of outcomes following failed spinal instrumentation with Polyetheretherketone rods and titanium rods. Spine (Phila Pa 1976). 2010;35(17):E843-8.

\section{Publisher's Note}

Springer Nature remains neutral with regard to jurisdictional claims in published maps and institutional affiliations.

Ready to submit your research? Choose BMC and benefit from

- fast, convenient online submission

- thorough peer review by experienced researchers in your field

- rapid publication on acceptance

- support for research data, including large and complex data types

- gold Open Access which fosters wider collaboration and increased citations

- maximum visibility for your research: over 100M website views per year

At BMC, research is always in progress.

Learn more biomedcentral.com/submissions 